\title{
LA URGENCIA EN EL «ITER LEGIS»: UNA TÉCNICA DE AGILIZACIÓN PROCEDIMENTAL A DISPOSICIÓN DEL GOBIERNO
}

\author{
POR \\ YOLANDA GÓMEZ LUGO \\ Profesora de Derecho Constitucional de la Universidad \\ Carlos III de Madrid
}

\section{LA URGENCIA COMO TÉCNICA DE AGILIZACIÓN PROCEDIMENTAL Y COMO INSTRUMENTO A DISPOSICIÓN DEL GOBIERNO}

Nuestro texto constitucional se inserta en la tendencia iniciada por las Constituciones de la segunda posguerra que incorporan técnicas procedimentales tendentes a la agilización en la aprobación de la ley. Combatir la lentitud propia de los procedimientos legislativos ${ }^{1}$, y las consecuencias que derivan de ello, así como alcanzar cierta celeridad de la actividad legislativa se ha convertido en algunas de las principales exigencias de los Parlamentos contemporáneos, para lo cual han sido creados diferentes mecanismos para simplificar el cauce ordinario

${ }^{1}$ Entre las obras generales sobre el procedimiento legislativo pueden consultarse GARCÍA MarTínez, M. A., El procedimiento legislativo, Madrid, Congreso de los Diputados, 1987; GARCÍAEscudero MÁrquez, Piedad, El procedimiento legislativo ordinario en las Cortes Generales, Madrid, Centro de Estudios Políticos y Constitucionales, 2006. 
previsto para la emanación legislativa. En esta línea son varios los ordenamientos jurídicos de nuestro entorno que contemplan diferentes procedimientos legislativos especiales por razón del tiempo de tramitación ${ }^{2}$, cuya singularidad reside en la capacidad para atenuar los trámites previstos por las normas reguladoras del iter legis común, pudiendo afectar bien a fases completas del procedimiento (la técnica de lectura única o delegación de competencia legislativa plena en Comisión), o bien a plazos del mismo (procedimiento de urgencia).

Las razones que justifican la búsqueda de la aceleración de los trámites legislativos son de naturaleza estrictamente política. La premura de la actividad legislativa puede venir motivada por la necesidad de resolver asuntos sobrevenidos o demandados socialmente, para dar curso a un texto sobre el que existe consenso político suficiente que haga innecesaria la celebración de todos los actos integrantes del iter legis, por el deseo de cumplir el programa político del Gobierno ante el final de una legislatura y la consiguiente disolución de las Cámaras, incluso por la pretensión de evitar el uso obstruccionista de algunos actos o trámites parlamentarios por parte de la oposición, ante la pretensión de la mayoría de sacar adelante los proyectos del Gobierno.

Además, estas técnicas procedimentales permitirán dotar de mayor flexibilidad a la actividad de la Cámara permitiendo la adaptación a las eventualidades que reclamen su intervención. Resulta evidente que la aplicación de estas variedades transmite mayor dinamismo al Parlamento al facilitar instrumentos aptos para ofrecer una respuesta legislativa ágil de los asuntos propuestos y, al mismo tiempo, otorga al Ejecutivo las condiciones y mecanismos necesarios para favorecer el cumplimiento de su programa político, ya que no puede omitirse que la mayor parte de estas técnicas se activan a instancia del Gobierno y la mayoría parlamentaria que lo sustenta. De este modo se constata que la previsión de este

${ }^{2}$ La sistematización de los procedimientos legislativos especiales que utilizaremos en este trabajo seguirá la clasificación propuesta por M.A. García Martínez, en virtud de la cual se van a distinguir dos variantes. Por una parte, se encuentran los procedimientos cuya especialidad deriva ratione materiae, esto es, se trata de modalidades particularizadas de tramitación para la regulación de determinados ámbitos materiales, por lo que tendrán carácter obligatorio, y entre los que cabría señalar los previstos para la aprobación de la Ley de presupuestos, las Leyes Orgánicas, la reforma de los Estatutos de Autonomía, la Ley de armonización,... De otra, se encuentran los procedimientos legislativos especiales por razón temporal, es decir, aquellas técnicas procedimentales tendentes a la aceleración de los actos parlamentarios que conforman el iter legis, con la pretensión de agilizar la emanación de las leyes, y que tienen carácter dispositivo o facultativo. Quedarían incluidos dentro de esta modalidad los siguientes métodos procedimentales: la delegación de competencia legislativa plena en las Comisiones parlamentarias, la técnica de lectura única y el procedimiento de urgencia. Sobre la clasificación de los procedimientos legislativos especiales propuesta por García Martínez consúltese, El procedimiento legislativo, op. cit. 
tipo de técnicas y procedimientos parlamentarios no sólo tiene como función lograr la agilización de la actividad legislativa de las Cámaras, sino que pretende igualmente mejorar el rendimiento de la misma, racionalizando el uso de los tiempos y permitiendo una mayor eficiencia en los trabajos legislativos; propósitos que se alcanzan mediante una correcta distribución de los mismos. Desde esta perspectiva, es indudable la relevancia que el factor temporal tiene en el desarrollo del quehacer parlamentario, convirtiéndose en un aspecto esencial en aras de la funcionalidad de la institución.

La función de estas técnicas procedimentales como instrumentos para combatir el obstruccionismo ${ }^{3}$ es clara, constituyendo buena muestra de ello la declaración de urgencia que el Gobierno puede presentar estando en curso el procedimiento legislativo durante cualquier momento de la tramitación ${ }^{4}$; supuesto del que nos ocuparemos detalladamente en este trabajo. En este sentido, métodos como el procedimiento de urgencia vienen a reforzar el papel del Ejecutivo en el iter legis, en la medida en que son mecanismos que le permiten acelerar la producción legislativa y, de este modo, dar cumplimiento a su programa político. Efectivamente, a nuestro modo de ver, los procedimientos legislativos especiales por razón temporal, y entre ellos el de urgencia, se convierten en instrumentos en los que se plasma la concepción del denominado Parlamentarismo racionalizado por la optó el constituyente español. A través de cualquiera de ellos (procedimiento de urgencia, lectura única o de delegación de competencia legislativa plena en Comisión) se reconocen ciertos privilegios al Ejecutivo para lograr una aceleración en los trámites que llevan a la emanación legislativas ${ }^{5}$.

3 Puede entenderse el obstruccionismo como «el uso de los mecanismos parlamentarios con el fin de obstaculizar la toma de decisiones por parte de las Cámaras». Cfr. TORRES MURO, I., «El obstruccionismo, un arma de las minorías», Revista de la Facultad de Derecho de la Universidad Complutense de Madrid, n. ${ }^{\circ} 83$ (anuario), p. 367.

${ }^{4}$ Sobre los distintos instrumentos dirigidos a acelerar la actividad legislativa a través de la limitación de las intervenciones que pueden obstaculizar la labor parlamentaria, cfr. REDONDO GARCIA, Ana María, El derecho de enmienda en los procedimientos legislativos de las Cortes Generales, Madrid, Congreso de los Diputados, 2001, pp. 88-92. Como se recoge en esta monografía, diferentes ordenamientos jurídicos han incorporado distintas modalidades de técnicas, entre las que se incluyen algunos procedimientos legislativos especiales, que favorecen «la celeridad en la aprobación de la ley reprimiendo cualquier maniobra obstruccionista pero también, en ocasiones impidiendo a las minorías una participación regular en los debates», op. cit., p. 89. Efectivamente, el problema de estos mecanismos reside, como señala A. Redondo García, en saber «discernir las tácticas obstruccionistas de otras prácticas de la oposición no abusivas o de mala fe, pero que igualmente pueden conducir a una ralentización del procedimiento de elaboración», p. 91.

5 Un análisis de las distintas manifestaciones del rol del Gobierno en la esfera del Parlamento desde las perspectiva del derecho comparado, puede consultarse en MASSA, Paolo, Parlamen- 
Ahora bien, debemos adelantar que el éxito de esta técnica de agilización procedimental no depende exclusivamente de su previsión normativa, sino de otros factores como su uso por las Cámaras y del ejercicio que los parlamentarios hagan de sus derechos inherentes al cargo que ostentan, puesto que el resultado final deriva de la actuación de aquellos a lo largo de la tramitación, en la medida en que no recurran a "discursos interminables con el fin de impedir el estudio y votación de un asunto».

Realizadas estas precisiones sobre el contexto en el que se inserta la categoría del procedimiento de urgencia, seguidamente pasamos a analizar su régimen jurídico en nuestro derecho positivo, destacando el papel preponderante del Gobierno en el mismo.

\section{MARCO NORMATIVO DE LA «URGENCIA»}

La Constitución no regula esta abreviación de la tramitación parlamentaria como un procedimiento legislativo aplicable por igual en ambas Cámaras, sino que únicamente incorpora dos breves referencias en su articulado, dirigidas a cada una de las Cámaras por separado. De una parte, en el artículo 86.3, y al hilo de la disciplina sobre la intervención parlamentaria en la tramitación del decreto-ley, contempla la existencia de un procedimiento de urgencia que sería aplicable a los decretos leyes que se sustanciasen como proyecto de ley dentro del plazo previsto para su convalidación por el Congreso de los Diputados. La norma simplemente reconoce la existencia de un procedimiento especial sin especificar las características de esta modalidad, por lo que la determinación de los trámites que lo conforman será desarrollada por el Reglamento del Congreso. De otra, el texto constitucional prevé la simplificación procedimental aplicable en la Cámara Alta al disponer que «el plazo de dos meses de que el Senado dispone para vetar o enmendar el proyecto se reducirá al de veinte días naturales en los proyectos declarados urgentes por el Gobierno o por el Congreso de los Diputados» (art. 90.3). En este supuesto, el precepto constitucional detalla la particularidad aplicable al procedimiento común, que servirá de soporte o estructura base.

Este modo de abordar la regulación de la declaración de urgencia, sin especificar su naturaleza, ha originado un debate doctrinal en torno a la considera-

tarismo razionalizzato e procedure parlamentare. Lineamenti di diritto parlamentare comparato, Milano, Giuffrè, 2003.

6 En este sentido ha sido entendido el fenómeno de los «filibusteros» por el Tribunal Constitucional. Ver ATC 135/2004, de 5 de agosto, f.j. $6^{\circ}$. 
ción de esta figura como un procedimiento legislativo especial autónomo, o bien como una mera regla de funcionamiento de las Cámaras, lo que ha dado lugar a ciertas dificultades de encaje técnico, en la medida en que existen motivos que dificultan su catalogación como procedimiento legislativo especial. Lo que sí podemos constatar es la creación constitucional de esta modalidad de tramitación, independientemente de lo que exponemos a continuación sobre su naturaleza, aunque cierto sector de nuestra doctrina sostiene que se trata de una variante creada por los Reglamentos parlamentarios, como locus adecuado para simplificar o acortar los trámites ${ }^{7}$. En nuestra opinión, no parece haber dudas para admitir que ha sido la voluntad del constituyente la que ha reconocido la existencia de esta modalidad en el Senado (art. 90.3 CE), si bien en el caso del Congreso de los Diputados es el Reglamento la fuente encargada de su creación, salvo el supuesto específico de conversión de decretos leyes que regula expresamente el artículo 86.3 CE.

\section{3. ¿PROCEDIMIENTO DE URGENCIA O NORMA DE FUNCIONAMIENTO?}

Esta peculiar regulación constitucional de la urgencia, y su desarrollo posterior por los Reglamentos parlamentarios, ha abierto una discusión sobre la posibilidad de que este acortamiento de plazos pueda considerarse criterio suficiente para catalogar esta forma de tramitación parlamentaria como procedimiento legislativo especial autónomo respecto al ordinario; problemática, planteada también en otros ordenamientos de nuestro entorno más cercano, como el italiano. Veamos cuál es el estado de la cuestión en nuestro derecho positivo.

Para abordar esta temática debemos analizar por separado la normativa recogida en los Reglamentos del Congreso y del Senado. Como hemos apuntado, la Constitución no regula formalmente la urgencia como "procedimiento» en sí, sino que simplemente reconoce la posibilidad de que los proyectos de ley sean declarados urgentes por el Gobierno o por el Congreso de los Diputados; esto es, existe una regulación constitucional de la declaración de urgencia, aunque no se configura jurídicamente como procedimiento específico de elaboración de leyes, con la excepción de la norma constitucional del artículo 86.3 CE aplicable exclusivamente en la Cámara baja. De igual manera, debemos reconocer que en el

7 Consúltese Ruiz Robledo, A., «Sobre los tipos de procedimientos legislativos» en $V$ Jornadas de Derecho Parlamentario. El Procedimiento legislativo, Madrid, Congreso de los Diputados, 1997, p. 661. 
caso de la modalidad contemplada por el artículo 75.2 CE (Comisión con competencia legislativa plena), la Constitución tampoco utiliza la expresión «procedimiento" para referirse a este modo particularizado de tramitación y aprobación legislativa, y sin embargo, nadie parece cuestionar la naturaleza procedimental de este modo de ejercicio de las competencias legislativas de las Cámaras.

A nuestro modo de ver, la raíz del problema se encuentra en la sistemática del Reglamento del Congreso, cuyo capítulo VI tiene como rúbrica «De la declaración de urgencia», y aparece dentro del Título IV dedicado a las disposiciones generales de funcionamiento, en lugar de situarse en el Título $\mathrm{V}$ donde se recogen las normas referentes al procedimiento legislativo. En opinión de cierto sector doctrinal, este tratamiento normativo resulta acertado, ya que se trata de un procedimiento distinto del ordinario; en esta línea se pronuncian autores como Villacorta Mancebo ${ }^{8}$ o Redondo García. A juicio de esta última, «la declaración de urgencia no constituye una especialidad en cuanto peculiaridad procedimental, puesto que lo que significa es únicamente la reducción de plazos a la mitad sin que se modifique la estructura del procedimiento previamente establecido que se desarrolla en todas sus fases pero con mayor celeridad $»$.

Esta postura se ve confirmada por la interpretación que del precepto constitucional (90.3 CE) ha hecho el Tribunal Constitucional al considerar que el enunciado «...pone de manifiesto que no constituye propiamente objeto del mismo la regulación de un procedimiento legislativo abreviado para la tramitación de proyectos normativos caracterizados por la urgencia. No existe en nuestro texto constitucional, a diferencia de lo que es el caso de otras Constituciones, un precepto que expresamente prevea el establecimiento de uno o varios procedimientos de tal carácter, por más que su concreta regulación se remita a una norma de desarrollo...» (STC 234/2000, F.J. 8º). Desde esta óptica, el supremo intérprete de nuestro texto constitucional sostiene que el apartado tercero del

${ }^{8}$ Villacorta Mancebo, L., Hacia el equilibrio de poderes. Comisiones legislativas y robustecimiento de las Cortes, Valladolid, 1989, p. 310. A su juicio, resulta más acertado el criterio empleado por el Reglamento del Congreso que «regula la declaración de urgencia en un capítulo separado - el VI-, dentro del Título IV, y aunque el artículo 93.1 del Reglamento del Congreso de los Diputados, en su inciso final, haga expresa mención del "Procedimiento de urgencia», todo parece indicar que en este Reglamento la declaración de urgencia se refiere a un aspecto formal que no altera la naturaleza del Procedimiento declarado urgente». Para el autor la razón de este planteamiento se encuentra en que la abreviación de los plazos no implica alteración de la naturaleza del procedimiento, por lo que en ningún caso podría considerarse como un procedimiento diferente, op. cit., pp. 444-445.

9 Véase, Redondo García, Ana María, El derecho de enmienda en los procedimientos legislativos de las Cortes Generales, op. cit., p. 102. 
artículo 90 contiene «una regla de reducción de plazos por la que se disminuye a veinte días el referido plazo ordinario de dos meses en el caso de los proyectos declarados urgentes...» (F.J. 8\%). El Tribunal Constitucional se está refiriendo probablemente a Constituciones como la italiana, cuyo artículo $72.2^{10}$ faculta a los Reglamentos parlamentarios para que puedan establecer procedimientos abreviados para aquellos proyectos de los cuales sea declarada la urgencia; sin embargo, a nuestro juicio, la ausencia de una norma como esta en nuestro texto constitucional, no es óbice para impedir el reconocimiento de variantes abreviadas en el ordenamiento jurídico español, entre otras razones, porque las Cámaras siempre pueden crear este tipo de instrumentos procedimentales a través del Reglamento parlamentario, y ello, en el ejercicio de su autonomía normativa y organizativa. Téngase en cuenta que los procedimientos legislativos especiales por razón temporal, entre los que incluimos el de urgencia, se distinguen de los especiales ratione materiae en la posibilidad de ser creados no sólo por las normas constitucionales, sino también por los Reglamentos parlamentarios ${ }^{11}$. Además, el efecto de los procedimientos abreviados italianos y el que produce la declaración de urgencia en nuestro sistema parlamentario es el mismo: reducción de los plazos previstos en el iter legis ordinario a la mitad. Independientemente de la denominación que se quiera emplear, a nuestro juicio nos encontramos ante un expediente técnico similar, que funciona impulsado por un presupuesto previo, la declaración de urgencia, y que produce los mismos efectos jurídicos, la atenuación temporal del procedimiento legislativo.

Otro argumento utilizado por Redondo García para descartar la consideración de la urgencia como procedimiento especial es la posibilidad de aplicar esta tramitación sobrevenidamente, esto es, «el hecho de que la urgencia pueda declararse una vez iniciado el procedimiento, redunda en la idea de que no estamos en presencia de un procedimiento legislativo especial sino que se trata de una decisión que afecta al procedimiento ordinario o especial que se ha elegido en base a las características de la materia o del objeto a regular» ${ }^{12}$. Ahora bien, a nuestro

${ }^{10}$ Artículo 72.2 de la Constitución italiana: «El Reglamento establecerá procedimientos abreviados para las propuestas de ley que se declaren urgente».

${ }^{11}$ El análisis de la cuestión en derecho parlamentario español revela como alguno de los procedimientos legislativos especiales por razón temporal ha sido creado por los Reglamentos parlamentarios, constituyendo un claro ejemplo de ello el procedimiento de lectura única, creado directamente por las normas reglamentarias, concretamente, por los artículos 150 RCD y 129 RS. De este modo, no existe óbice alguno que impida la creación ex novo, como sostiene Ruíz Robledo, de algunas categorías de procedimientos legislativos. Sobre ello, cfr. RuIz RoblEDO, Agustín, «Sobre los tipos de procedimientos legislativos», en V Jornadas de Derecho Parlamentario. El procedimiento legislativo, Madrid, Congreso de los Diputados, 1997, p. 661.

12 Redondo García, Ana María, op. cit., p. 103. 
modo de ver, esta consideración parte de un presupuesto equivocado, como es circunscribir los denominados procedimientos legislativos especiales a aquellas particularidades de la tramitación parlamentaria determinadas exclusivamente por razón de la materia objeto de regulación y que se aplican exclusivamente desde el inicio de la tramitación en la Cámara; acotamiento que no encaja con la definición de procedimiento legislativo especial que sostenemos, la cual abarca también aquellos otros especiales por razón temporal. A nuestro modo de ver, resulta perfectamente admisible la aplicación sobrevenida de algunas especialidades procedimentales, como se desprende de diferentes normas de nuestro Derecho parlamentario ${ }^{13}$.

Existe, además, otro argumento que nos lleva a defender esta tesis a favor de la urgencia como procedimiento legislativo especial, y es que no resulta equiparable la mera prórroga o acortamiento ordinario de plazos aplicables a trámites concretos de un procedimiento parlamentario a la activación de la modalidad de urgencia, de aplicación genérica y con alcance a todos los trámites y actos integrantes del iter que restan hasta la finalización de la tramitación parlamentaria.

Villacorta Mancebo entiende que «de admitirse que la mera declaración de urgencia - con acortamiento de plazos - supone un cambio de Procedimiento Legislativo, puede llegarse en último extremo a la absurda conclusión, de que, por ejemplo, siempre que se produzca una prórroga expresa del plazo de presentación de enmiendas o una transgresión de los plazos en cualquiera de los momentos o trámites del Procedimiento ... estaríamos en presencia de un nuevo Procedimiento» ${ }^{14}$. Sin embargo, pese a que la Constitución no ha reconocido de forma explícita la existencia de un procedimiento de urgencia, del contenido de los artículos 90.3 y 86.3 CE puede deducirse este reconocimiento. Por lo que

${ }^{13}$ Son varios los ejemplos previstos en los que se permite la alteración del procedimiento incoado el mismo retrotrayendo o no la tramitación, según los casos, a un trámite anterior. La rectificación de la calificación inicial de una iniciativa según lo dispuesto en el artículo 130 RCD y su recalificación en iniciativa de ley orgánica, con la consecuente modificación del procedimiento. Otro supuesto sería el que deriva de la potestad del Pleno de avocar para sí las facultades aprobatorias o resolutorias sobre un proyecto o proposición de ley en tramitación, cuando se hubiera optado previamente por el procedimiento de delegación con competencia legislativa plena en Comisión (arts. 149.1 RCD y 130.2 RS). Y por último, respecto al procedimiento de urgencia que nos ocupa y como se verá detenidamente en este trabajo, el artículo 93.2 del Reglamento del Congreso de los diputados permite la adopción del mismo "hallándose un trámite en curso", esto es, incoado un procedimiento legislativo la Mesa de la Cámara, a petición del Gobierno, dos grupos parlamentarios o una quinta parte de los diputados, pueden decidir que el asunto se sustancie por esta modalidad procedimental, siendo de aplicación a partir de los trámites siguientes sin posibilidad de retrotraer el procedimiento.

${ }^{14}$ Véase Villacorta Mancebo, op. cit., p. 445. 
respecta a la normativa reglamentaria, en el caso del Congreso debe tenerse en cuenta que, aunque en la rúbrica no se haya mencionado la referencia al "procedimiento", el contenido del artículo 93.1, en su inciso final, se refiere expresamente al "procedimiento de urgencia» (en el mismo sentido que la normativa del Reglamento provisional del Congreso de 1977, si bien éste lo incluía en el Capítulo II del Título Sexto sobre procedimiento legislativo). Ahora bien, en el supuesto del Reglamento del Senado, es más difícil incluso negar la existencia de un procedimiento especial separado del iter legis común, en la medida en que la propia normativa reglamentaria regula expresa y detalladamente en la sección tercera del capítulo II del Reglamento del Senado, sobre los «procedimientos legislativos especiales", el denominado "procedimiento de urgencia» (artículos 133 a 136), incluyendo un procedimiento autónomo, variante de este último, y que analizaremos seguidamente. Así pues, tanto de las normas del Reglamento del Senado, como del artículo 90.3 CE se deriva el reconocimiento de una variante de tramitación y aprobación legislativa, diferente y alternativa al procedimiento legislativo común.

En consecuencia, no podemos compartir la línea argumental sostenida en la STC 234/2000 en la que se niega la existencia en nuestro Derecho parlamentario de un procedimiento de urgencia particularizado y se confirma este tratamiento jurídico como norma de funcionamiento consistente en regla de reducción de plazos. En nuestra opinión, la reducción de plazos a la mitad o a veinte días, constituye una afección importante al significado de algunos trámites del procedimiento. El acortamiento de los plazos que conlleva la «declaración de urgencia» es bastante rígido, lo suficiente para afectar a la naturaleza del procedimiento convirtiéndolo en una tramitación que se aparta del procedimiento legislativo común, no tanto por razones cuantitativas como cualitativas, en la medida en que en dicha modalidad de elaboración de leyes la minoría parlamentaria verá disminuida su posibilidad de participación, como veremos.

Realizadas estas consideraciones, entendemos que la «urgencia» encaja perfectamente en el concepto de procedimiento legislativo especial por razón temporal que proponemos, por lo que desde esta perspectiva la misma aparece configurada en nuestro Derecho parlamentario como tal, y no como mera norma de funcionamiento de la Cámara. Por tanto, nos encontramos con una modalidad procedimental particularizada, cuya especialidad consiste en la atenuación de la tramitación parlamentaria, sin que ello implique supresión alguna de las fases del procedimiento, sino una reducción de los plazos previstos para el iter legis ordinario, lo que constituye una restricción drástica de la secuencia temporal. Por lo demás, la estructura del procedimiento se mantiene intacta, esto es, el orden de trámites y etapas que se suceden para la emanación de la ley no se ve alterado. 


\section{EL PROCEDIMIENTO DE URGENCIA EN LAS CORTES GENERALES}

\subsection{Introducción}

Las fuentes normativas de esta variante del iter legis se encuentran tanto en la Constitución, donde encontramos las normas que crean el procedimiento, como en los Reglamentos parlamentarios cuyas previsiones detallan las reglas particularizadas de esta tramitación. Por tanto, podemos afirmar sin duda alguna que se trata de un procedimiento con «apoyatura constitucional», como ha reconocido P. García-Escudero Márquez ${ }^{15}$, cuyo reconocimiento deriva de los artículos 90.3 y 86.3 CE.

Por su parte, los Reglamentos parlamentarios incorporan la normativa que desarrolla los trámites especiales de esta modalidad. Respecto a su ubicación, en el caso del Reglamento del Congreso no se regula en el Título V sobre el Procedimiento Legislativo, sino que se incorpora en el Título IV sobre las disposiciones generales de funcionamiento, en el capítulo VI rubricado "De la declaración de urgencia». En cambio, el Reglamento del Senado introduce esta regulación en el Título IV ("Del procedimiento legislativo»), concretamente en el Capítulo II ( De los procedimientos legislativos especiales»). En nuestra opinión, esta segunda opción resulta más adecuada con la naturaleza de la urgencia como procedimiento legislativo especial, y más acorde con los preceptos constitucionales, por lo que sería aconsejable que la futura reforma del Reglamento del Congreso incorporase la normativa de esta técnica procedimental junto a las restantes especialidades del iter legis.

\subsection{La especialidad procedimental}

Hemos catalogado el procedimiento de urgencia como modalidad especial de elaboración legislativa por razón del tiempo de tramitación. En este supuesto la especialidad o tipificación procedimental no actúa sobre los trámites que integran el iter legis, sino sobre los plazos y tiempos generales previstos para el procedimiento común que sirve de base.

De la regulación del Reglamento del Congreso de los Diputados se deduce que la principal característica de este procedimiento en la Cámara baja consiste

15 Véase en García-Escudero MÁrquEZ, Piedad, «El procedimiento legislativo en las Cortes Generales. Regulación, fases y tipos», Teoría y Realidad Constitucional, n. ${ }^{\circ}$ 16, 2005, p. 236. 
en la reducción a la mitad de los plazos establecidos para el procedimiento legislativo ordinario (art. 94) ${ }^{16}$, manteniendo todas las fases previstas para éste, si bien la especialidad afectará a todos los momentos de Ponencia, Comisión y Pleno. La aplicación de esta norma implica una disminución del tiempo destinado al examen de la iniciativa, a la presentación y votación de las enmiendas, así como una reducción de la duración de las intervenciones, discusión y votación del texto definitivo; limitaciones, que afectan directamente al ejercicio de los derechos de los parlamentarios en el seno del procedimiento legislativo y que en el caso del Senado producirá unos efectos más drásticos.

Efectivamente, en el caso del Senado las previsiones constitucionales y reglamentarias establecen que la duración de la tramitación quedará reducida a veinte días naturales, frente a los dos meses que dura en el procedimiento ordinario, como se desprende del artículo 90.2 de la Constitución. En consecuencia, el lapso temporal de la secuencia procedimental se repartirá del siguiente modo: el plazo para la presentación de enmiendas quedará reducido a cuatro días (artículo 133.1 RS), el mismo de que dispondrá la Ponencia para emitir su Informe (artículo 133.2 RS). A los tres días de concluido éste se reunirá la Comisión para emitir su dictamen en el plazo de dos días (artículo 133.3 RS). Respecto a la deliberación en el Pleno, aunque en principio se rige por las normas del procedimiento legislativo ordinario, la Mesa tiene la facultad de modificar la duración de las intervenciones cuando así lo aconseje el desarrollo de los debates (artículo 133.4 RS). También podrá la Mesa modificar los plazos cuando así lo aconsejen las circunstancias del proyecto (artículo 133.6 RS), ampliando o reduciendo los mismos.

Así pues, a través de estas normas se establecen los límites máximos para el desarrollo de cada uno de los trámites señalados, con la única excepción del debate plenario que, pese a no tener determinado ningún límite temporal tasado, se celebrará durante el tiempo restante hasta el transcurso de los veinte días que dura la tramitación en la Cámara Alta.

Ahora bien, debemos tener en cuenta un dato fundamental y es que en ambas Cámaras el acortamiento de la tramitación que implica el procedimiento de urgencia es perfectamente compatible con la aplicación de las reglas generales de ampliación o reducción de tiempos previstas por el Derecho parlamentario; en este sentido se pronuncian expresamente los Reglamentos parlamentarios. En el caso del Senado, las normas reglamentarias permiten el acortamiento de cual-

16 Artículo 94 del Reglamento del Congreso de los Diputados: «Sin perjuicio de lo establecido en el artículo 91 del presente Reglamento, los plazos tendrán una duración de la mitad de los establecidos con carácter ordinario». 
quiera de los límites máximos fijados por las reglas previstas en el artículo 133, por lo que, de aplicarse esta norma, el Pleno podría beneficiarse de esta agilización al contar con más tiempo disponible para celebrar el debate. Efectivamente, la aplicación de esta atenuación procedimental es perfectamente compatible con la regla general de reducción de tiempos ${ }^{17}$ prevista por los Reglamentos parlamentarios, como se desprende del artículo 94 RCD al prever que «sin perjuicio de lo establecido en el artículo 91 del presente Reglamento, los plazos tendrán una duración de la mitad de los establecidos con carácter ordinario» y del artículo 135.6 RS al disponer que «La Mesa podrá acordar modificaciones en los plazos cuando así lo aconsejen las circunstancias».

Por último, cabe la posibilidad de que el procedimiento de urgencia sea declarado una vez iniciada la tramitación de un texto, esto es, sobrevenidamente, siendo de aplicación las especialidades de esta tramitación al resto de fases que queden hasta la adopción del texto, sin retrotraer el procedimiento al momento de la incoación del mismo.

\section{3. Órgano legitimado para la activación del procedimiento de urgencia}

La decisión sobre la tramitación conforme al procedimiento de urgencia puede adoptarse tanto a petición de determinados órganos parlamentarios, como por iniciativa de sujetos ajenos a las Cámaras.

El Reglamento del Congreso atribuye la capacidad para adoptar la tramitación de urgencia a órganos exclusivamente parlamentarios, al señalar como sujeto legitimado para instar la activación de esta modalidad procedimental a la Mesa de la Cámara, a propuesta del Gobierno, dos Grupos parlamentarios o una quinta parte de los diputados (art. 93.1 RCD) ${ }^{18}$. Por tanto, en esta Cámara el órgano rector de la misma será el encargado de aplicar esta variante, si bien no podrá hacerlo de oficio, sino siempre a instancia de los sujetos señalados en el precepto anterior.

La normativa del Reglamento del Senado admite no sólo el origen parlamentario de la decisión sobre la urgencia, sino también la activación procedi-

17 Artículo 91.1 RCD:

«1. La Mesa de la Cámara podrá acordar la prórroga o reducción de los plazos establecidos en este Reglamento.

2. Salvo casos excepcionales las prórrogas no serán superiores a otro tanto del plazo ni las reducciones a su mitad».

18 Artículo 93.1 RCD: «A petición del Gobierno, dos Grupos Parlamentarios o de una quinta parte de los Diputados, la Mesa del Congreso podrá acordar que un asunto se tramite por procedimiento de urgencia». 
mental mediante la declaración procedente de órganos ajenos a la Cámara Alta. Efectivamente, podemos distinguir en esta regulación dos grupos de sujetos legitimados para poner en marcha este cauce procedimental. De una parte, se atribuye a la Mesa del Senado la potestad de activarlo de oficio, o bien a propuesta de un Grupo parlamentario o veinticinco senadores (art. 133.2 RS). Y de otra, se reconoce al Gobierno y Congreso de los Diputados la capacidad para declarar la urgencia; instancias, ajenas a la Cámara en la que se tramita el texto.

Comenzando por la primera de las opciones, el Reglamento amplía el elenco de sujetos legitimados por el artículo $90.3 \mathrm{CE}^{19}$ para instar el procedimiento, admitiendo que la decisión sobre la tramitación de urgencia pueda ser adoptada directamente por órganos pertenecientes a la Cámara, y ello, independientemente de la modalidad de tramitación del texto seguida en el Congreso de los Diputados. En esta ocasión la novedad que aporta la normativa del Reglamento del Senado se encuentra en la posibilidad de que el órgano rector actúe no sólo a propuesta de un grupo parlamentario o veinticinco senadores, sino también de oficio (art. 133.2 RS) ${ }^{20}$. Esta atribución de la Mesa para fijar el procedimiento aplicable, supone un refuerzo de los poderes de dirección de la actividad legislativa por parte del órgano rector que puede incluso actuar a instancia propia; posibilidad que, sin embargo, el Reglamento del Congreso no reconoce a la Mesa. A nuestro modo de ver, en este supuesto se produce una ligera variación en el alcance de las funciones de la Mesa; ésta deja de actuar como mero órgano técnico en el ejercicio de su potestad de decidir sobre la tramitación, en la medida en que no se limita a llevar a cabo solamente un juicio de procedibilidad ${ }^{21}$. En el caso que nos ocupa, la Mesa va más allá, viendo reforzadas sus atribuciones para decidir sobre la tramitación, puesto que la normativa vigente permite que actúe con mayor margen de discrecionalidad participando activamente en la tramitación legislativa. El Reglamento del Senado, al prever la activación de oficio

19 Artículo 90.3 CE: «El plazo de dos meses de que el Senado dispone para vetar o enmendar el proyecto se reducirá al de veinte días naturales en los proyectos declarados urgentes por el Gobierno o por el Congreso de los Diputados».

20 «Asimismo, la Mesa del Senado, de oficio o a propuesta de un Grupo parlamentario o de veinticinco senadores, podrá decidir la aplicación del procedimiento de urgencia».

${ }_{21}$ Téngase en cuenta que el acuerdo sobre la tramitación de escritos y documentos de índole parlamentaria constituye un acto necesario y predeterminado jurídicamente consistente en dar curso a los trámites imprescindibles para la prosecución del iter legis, subsumiendo la iniciativa en el procedimiento reglamentariamente previsto. Esta labor de identificación procedimental tiene lugar, bien por razón del objeto material de la iniciativa y de la calificación otorgada por la Mesa, o bien porque haya sido presentada la propuesta de tramitación conforme a un procedimiento específico a instancia de los sujetos legitimados. En cualquier caso, insistimos en el carácter jurídico de esta decisión que debe ser acordada conforme a Derecho. 
por la Mesa, elimina el trámite previo de la necesaria «propuesta de tramitación» por parte de otros sujetos, por lo que aquella acuerda por sí misma la aplicación de este procedimiento especial sin tener que tramitar esta propuesta de aplicación del procedimiento de urgencia y decidir sobre la misma. Por tanto, la diferencia entre los dos supuestos, actuación de oficio o a instancia de los órganos legitimados, se sitúa en el distinto margen de maniobra de la Mesa, lo que a su vez transmite un mayor dinamismo a la actividad de la Cámara.

Desde este punto de vista, el fundamento del artículo 133.2 RS adjudicando a la Mesa de la Cámara la capacidad para aplicar de oficio el procedimiento de urgencia parece encaminarse hacia un reforzamiento del papel del Senado en la función legislativa de las Cortes Generales, teniendo en cuenta las condiciones y limitaciones temporales impuestas por las fuentes parlamentarias a la Cámara Alta. Al permitir la activación de la urgencia, no sólo previa petición de otros sujetos como un grupo parlamentario o veinticinco senadores, sino también cuando la Mesa del Senado lo acuerda de oficio, se está abriendo un cauce más flexible que permite un acortamiento de la tramitación legislativa. Recuérdese que el plazo máximo para el desarrollo de todos los actos que llevan a la aprobación del texto conforme a esta técnica procedimental es de veinte días naturales, por lo que atribuir esta capacidad al órgano rector supone economizar tiempos y trámites previos al acuerdo de la urgencia. Con ello el Senado cuenta con un margen temporal más amplio para tramitar la iniciativa, puesto que a los veinte días se descontaría el tiempo destinado por la Cámara a la admisión a trámite y resolución de la propuesta cuando ésta procede de otros sujetos —un grupo parlamentario o veinticinco senadores-. A ello debemos añadir que aunque el artículo 133.2 RS no especifica el momento a partir del cual comienza el cómputo de los veinte días naturales, será de aplicación la regla general del artículo 106 RS, en virtud de la cual el plazo de que dispone la Cámara Alta para aprobar, enmendar o vetar la propuesta legislativa comienza a contar «a partir del día de la recepción del texto».

Además, debe tenerse en cuenta que cuando la Mesa de la Cámara acuerda el procedimiento de urgencia a iniciativa de los grupos parlamentarios o del número exigido de miembros de la Cámara de que se trate, sea en el Congreso o en el Senado, lo hace con carácter facultativo o, al menos, así se deduce de la normativa de los Reglamentos de ambas Cámaras al prever que la Mesa "podrá» acordar o decidir la aplicación del procedimiento de urgencia (arts. 93.1 RCD y 133.2 RS). En este segundo supuesto, lo que resulta obligado es la propuesta de tramitación, al menos en el Congreso donde el órgano rector tiene vedado decidir de oficio, pero la decisión final acordando la tramitación de urgencia corresponde a la Mesa de la Cámara. 
La segunda eventualidad es fruto de la norma contenida en el artículo 90.3 CE que habilita al Congreso de los Diputados y al Gobierno para intervenir en la actividad legislativa del Senado decidiendo sobre la técnica procedimental que éste deberá seguir para la tramitación del texto. En virtud de lo dispuesto en dicho precepto, ambos quedan facultados para declarar la urgencia, por lo que en los «proyectos declarados urgentes por el Gobierno o por el Congreso de los Diputados, el Senado dispone de un plazo de veinte días naturales para ejercitar sus facultades de orden legislativo" (Art. 133.1 RS). En estos supuestos nos encontramos ante la aplicación del procedimiento de urgencia de carácter automática y obligada por impulso de instancias ajenas al Senado, esto es, la mera declaración de la urgencia por iniciativa de los órganos señalados activa directamente la modalidad en el Senado sin necesidad de trámite añadido y sin que la Mesa pueda oponerse a la solicitud presentada.

Este automatismo constituye una excepción a una de las reglas generales de los procedimientos especiales por razón temporal, el carácter dispositivo o facultativo de su activación para la Cámara en la que se tramita el proyecto o proposición de ley. Téngase en cuenta que, a diferencia de las especialidades procedimentales ratione materiae, las particularidades derivadas del elemento tiempo otorgan a las Cámaras mayor libertad de elección de la modalidad procedimental a seguir para la tramitación de la iniciativa legislativa. Por otra parte, esta libertad se traduce en una ausencia de vinculación procedimental entre la modalidad de tramitación seguida en el Congreso y la acordada en el Senado; no obstante, esta norma quiebra en el caso que nos ocupa, esto es, cuando el Congreso ha tramitado un proyecto conforme al procedimiento de urgencia, quedando la Cámara Alta obligada a seguir la misma modalidad para la tramitación del texto en dicha sede.

Esta regulación ha suscitado algunas dudas doctrinales acerca de las potestades de la Mesa ante un hipotético uso indebido por parte del Gobierno al ejercer su facultad de declarar la urgencia. Concretamente Basterra Montserrat plantea la posibilidad de que la Mesa deniegue la tramitación del procedimiento «...si el Gobierno remite con carácter de urgencia todos sus proyectos de ley, llegando a abusar de esta facultad.... ${ }^{22}$. Se trata de un supuesto de hecho no contemplado por el texto constitucional, ni por los Reglamentos parlamentarios por lo que, en opinión de este autor, "debe entenderse que la Mesa, por razón del principio de autonomía normativa de las Cámaras, podría denegar, en determinados casos, dicha facultad, ya que cada Cámara tiene la autonomía de, en de-

${ }^{22}$ Consúltese Basterra MontSerrat, Las Comisiones legislativas con delegación plena, Granada, 1997, Comares, p. 94. 
fecto de normación constitucional, proveer a disciplinar el procedimiento legislativo ${ }^{23}$. Esta postura doctrinal se funda en la discrecionalidad con la que cuenta el órgano rector para seleccionar los procedimientos legislativos, por lo que Basterra sostiene que «siempre que la Constitución no lo prescriba de forma directa y expresa, quiere decir que en este caso puede declarar la urgencia y puede negarla llegado el caso».

En el supuesto de hecho planteado, se trata de dilucidar cuál es el alcance de las potestades del órgano rector una vez declarada la urgencia por uno de los sujetos legitimados, en este caso, el Gobierno; o expresado en otros términos, si la Mesa tiene que dar curso obligatoriamente a la tramitación de urgencia o bien puede denegarla. Nos encontramos ante el ejercicio de las facultades de calificación, admisión a trámite y decisión de la tramitación que corresponden a la Mesa de la Cámara. De las normas reguladoras de estas potestades se deduce que nos encontramos ante trámites preordenados jurídicamente e imprescindibles para la prosecución del procedimiento, cuya correcta aplicación es fundamental para lograr un uso adecuado de los procedimientos legislativos. La Mesa no sólo procede a la calificación y admisión a trámite de los escritos y documentos parlamentarios, sino que también decide sobre la tramitación de los mismos, procediendo a la fijación de la modalidad procedimental concreta, y es precisamente este momento el que nos interesa en el supuesto planteado. Ahora bien, el alcance de las facultades de la Mesa al seleccionar el procedimiento por el que se tramitará la iniciativa variará en función del tipo de especialidad procedimental, esto es, dependerá del tipo de procedimiento concreto.

En el caso de los procedimientos especiales por razón del tiempo de tramitación, como es el caso del procedimiento de urgencia, la labor fiscalizadora de la Mesa se limita a supervisar los requisitos formales previstos por la Constitución y los Reglamentos, y de este modo, valorar la idoneidad del procedimiento solicitado; esto es, procedería a la verificación de las exigencias relativas a la legitimidad de los sujetos, condicionantes temporales, así como a las materias excluidas de estas modalidades de tramitación, si las hubiere. Pues bien, teniendo presentes estas consideraciones acerca del alcance de las potestades de la Mesa sobre el acuerdo de tramitación, y en ausencia de previsiones constitucionales o reglamentarias que permitan a ésta denegar la urgencia declarada por el Gobierno, no podemos compartir la solución aportada por Basterra. A nuestro modo de ver, el órgano rector debe limitarse a la recepción de la declaración de urgencia y supervisar las exigencias previstas por las fuentes parlamentarias, que en este supuesto son mínimas, por lo que prácticamente se limitaría a fiscalizar la legiti-

\footnotetext{
23 En Basterra Montserrat, op. cit., p. 94
} 
midad del sujeto que declara la urgencia y, una vez comprobado la licitud de la declaración acordada por el Gobierno, debe dar curso a la misma fijando las reglas de este cauce procedimental. No existe norma en nuestro Derecho positivo que habilite a la Mesa para oponerse a dicha solicitud concurriendo los requisitos previstos por el ordenamiento. Recuérdese que la labor de la Mesa sigue siendo estrictamente jurídica, y salvo que los Reglamentos parlamentarios ante la ausencia de condicionantes por la Constitución opten por incorporar algún tipo de limitación en este sentido, aquella no puede denegar la solicitud.

Por último, y respecto al significado del reconocimiento constitucional al Gobierno de la facultad de declarar la urgencia, como medio de agilización del iter legis el Tribunal Constitucional ha declarado que se trata de una "opción del constituyente por un determinado entendimiento en las relaciones entre las Cortes Generales y el Gobierno a través de un mecanismo que permite a éste actuar sobre el procedimiento legislativo influyendo en su desarrollo cronológico cuando, en su criterio, concurran las circunstancias que así lo requieran» (STC 234/2000, FJ 10).

\subsection{La declaración de Urgencia}

Tanto la normativa constitucional como las previsiones de los Reglamentos parlamentarios supeditan la aplicación de esta modalidad procedimental a la declaración de urgencia, por lo que ésta se presenta como el acto de naturaleza política que impulsa la activación de la especialidad y cuya adopción corresponde a los sujetos legitimados por las fuentes parlamentarias. Desde esta perspectiva, puede afirmarse que la declaración de urgencia se convierte en el fundamento habilitante de este mecanismo procedimental. En consecuencia, se presenta como requisito previo y necesario, cuya concurrencia deberá verificar la Mesa de la Cámara antes de iniciar los trámites propios del procedimiento de urgencia.

Mas complicado resulta elaborar una definición material de la declaración de urgencia, esto es, intentar delimitar cuál debe ser el contenido de la misma. En realidad, ésta viene constituida por las razones fácticas que llevan a los órganos habilitados para declararla y proponer la aceleración de la tramitación. Son los sujetos legitimados para declarar la urgencia, (Gobierno, Congreso de los Diputados y Mesa de la Cámara) quienes deciden cuando concurre la misma, y ello conforme a criterios de mera oportunidad política.

Lo que parece indudable es que esta "declaración de urgencia» sólo puede acordarse ante circunstancias que requieren de cierta celeridad en su resolución legislativa, situaciones imprevistas o excepcionales que no pueden esperar el des- 
arrollo de la secuencia de actos de que consta el iter legis común, o incluso, que ante una hipotética disolución de las Cámaras, la resolución del asunto legislativo no puede esperar la celebración de la convocatoria electoral y la formación de las nuevas Asambleas. En nuestra opinión, estos supuestos de hecho se darían ante cualquier necesidad de actuación legislativa del Parlamento en un plazo inferior a cualquiera de los que ofrece el resto de modalidades procedimentales. De este modo, quedaría justificada la utilización de este cauce procedimental, cuando se requiriera la adopción de medidas normativas de forma inmediata por parte del Parlamento por excepcionales circunstancias políticas, resultando indispensables para satisfacer determinadas necesidades sociales y políticas que no pudieran esperar al normal desarrollo legislativo, que habitualmente se caracteriza por su lentitud. Parece deducirse que la voluntad de declarar la urgencia, como acto que activa el mecanismo procedimental, constituye en realidad una valoración política por parte de los sujetos legitimados por el ordenamiento a tal efecto.

Veamos ahora cuál es el papel de la Mesa en su faceta de órgano receptor de la petición para cursar la declaración de urgencia, y no como promotora de la misma. En este supuesto, el órgano rector actúa dando cumplimiento a una serie de competencias predeterminadas jurídicamente: recepción, calificación, admisión a trámite y decisión sobre la tramitación de escritos y documentos parlamentarios. En consecuencia, no podrá controlar jurídico-materialmente el contenido de la declaración de urgencia, por lo que, recibido el escrito con la declaración de urgencia procedente de cualquiera de los sujetos legitimados, deberá limitarse a constatar los requisitos formales exigidos por el ordenamiento, que prácticamente se limita a la concurrencia de la legitimación, esto es, verificará el Acuerdo del Consejo de Ministros o el escrito de la Presidencia del Congreso de los Diputados, dependiendo del caso, admitiéndolo a trámite y dando curso a la tramitación requerida, sin posibilidad de denegar dicha petición. Por tanto, de esta normativa se constata nuevamente que la declaración de urgencia por parte de la Cámara baja o del Gobierno constituye un supuesto de aplicación automática de esta modalidad de iter legis. Esta regla viene a confirmar una vez más la opción de nuestro constituyente por un bicameralismo imperfecto a favor del Congreso que, en este supuesto, incide directamente en la modalidad de tramitación que el Senado debe aplicar para aprobar la legislación proyectada.

Cuando es el Gobierno quien actúa como promotor de la urgencia, la justificación del automatismo de la decisión gubernamental de declararla procede de las facultades inherentes a su función de indirizzo politico ${ }^{24}$. Entre las muchas

${ }^{24}$ Entre las normas constitucionales que distribuyen las funciones estatales el artículo $97 \mathrm{CE}$ prevé la denominada función de dirección política del Gobierno; dirección política, como equi- 
manifestaciones de ejercicio de este cometido, el Gobierno puede hacer uso de esta posibilidad para agilizar la adopción de medidas que permitan el cumplimiento de su programa político dando impulso y orientación a la actividad estatal. De ahí, que admitir un control parlamentario sobre la decisión gubernamental, con el consiguiente rechazo de la declaración acordada, pudiera interpretarse como una usurpación de la función de dirección política, esto es, el Parlamento se habría inmiscuido en el ámbito de competencias que la Constitución reconoce al Gobierno, como efectivamente sucedió en el supuesto de hecho que resuelve la STC 234/2000.

De este modo, podemos afirmar que nos encontramos ante un instrumento que permite al Ejecutivo intervenir activamente e influir en el ejercicio de la función legislativa que el artículo 66.1 CE atribuye a las Cámaras parlamentarias, lo que a su vez se inserta entre las diferentes manifestaciones del parlamentarismo racionalizado incorporadas en nuestra Constitución. Desde esta perspectiva puede afirmarse que se trata de un instrumento a disposición del Gobierno para «actuar sobre el procedimiento legislativo influyendo en su desarrollo cronológico cuando, en su criterio, concurran las circunstancias que así lo aconsejen» (STC 234/2000, FJ $10^{\circ}$ ). Por otra parte, nuestra Jurisprudencia constitucional ha vinculado esta facultad gubernamental al ejercicio de la función de dirección política del Gobierno, al reconocerse que se trata de un cauce que le permite «acelerar o abreviar en determinadas circunstancias la tramitación parlamentaria de un proyecto de ley para el desarrollo de su función de dirección política (art. 97 CE)» (STC 234/2000, FJ 12\%).

Fuera de estos supuestos, cuando es la Mesa de la Cámara quien actúa de oficio, en el caso del Senado, o a petición de los grupos parlamentarios o del número de parlamentarios exigidos por los Reglamentos, entendemos que las circunstancias fácticas quedarán en última instancia a la libre apreciación de la Mesa de la Cámara correspondiente ya que, como se desprende de los artículos 93.1 RCD y 133.2 RS, ésta "...podrá...» acordar la tramitación de un asunto por el procedimiento de urgencia, con lo cual nos encontramos ante una facultad discrecional de la Mesa y ante una petición que puede ser denegada.

valente a orientación e impulso, lo que «supone una capacidad de señalar metas, disponer los medios para alcanzarlas, y fijar las prioridades en el uso de dichos medios. Trasladando el término al ámbito político, significa, por una lado, una acción creadora e independiente, no determinada por instrucciones o mandatos de otros (actividad libre) y, por otro, actividad de relación con sujetos muy distintos, y que puede expresarse en maneras diversas, con mayor o menos formalización jurídica» (LÓPEZ Guerra, Luis, «Dirección Política», en Aragón Reyes, Temas básicos de Derecho Constitucional, Tomo II, Madrid, Civitas, 2001, p. 209. 


\subsection{Ausencia de limites materiales}

Uno de los rasgos más llamativos de esta técnica procedimental es la ausencia de condicionantes materiales en las normas constitucionales y parlamentarias; condicionantes, que pudieran condicionar su activación para legislar determinados contenidos. Por una parte, el procedimiento de urgencia puede aplicarse a cualquier propuesta legislativa. En cuanto al tipo de iniciativa legislativa, entendemos que el artículo 133.2 RS se refiere tanto a proposiciones como a proyectos de ley, ya que a diferencia del supuesto previsto en el párrafo primero del mismo precepto, en el que alude exclusivamente a "proyectos», en esta ocasión simplemente no especifica nada al respecto. Por otra, a diferencia de lo que ocurre con otras especialidades por razón del tiempo de tramitación, como la Comisión con competencia legislativa ${ }^{25}$, en este supuesto no se excluyen materias de ser tramitadas y aprobadas conforme a las reglas de este procedimiento. Desde esta perspectiva, puede afirmarse que se trata de una modalidad caracterizada por el carácter genérico de su ámbito de aplicación, en la medida en que permite su activación a cualquier tipo de propuesta legislativa, proyecto o proposición de ley, independientemente del contenido material de ésta, lo cual dota de mayor flexibilidad y agilidad a la tramitación y actividad legislativa de las Cámaras. Esta característica viene a confirmar la admisibilidad de la simultaneidad de procedimientos especiales por razón material con aquellos cuya peculiaridad deriva del tiempo de tramitación, salvo aquellos supuestos excluidos expresamente. Sin embargo, esta posibilidad no impide que nos cuestionemos si sería aconsejable incorporar en nuestro ordenamiento alguna excepción a esta regla general de ausencia de límites materiales al procedimiento de urgencia, que es el que nos ocupa.

Resulta indudable que esta opción de la ausencia de límites materiales proporciona a las Cámaras técnicas aptas para actuar con flexibilidad frente a exigencias sobrevenidas necesitadas de respuesta legislativa. Un mecanismo como la tramitación de urgencia dota al Legislador de una mayor capacidad de actuación, permitiendo también economizar tiempos y trámites innecesarios cuando las circunstancias así lo aconsejan; piénsese, por ejemplo, en el supuesto de una ley aprobada por procedimiento particularizado ratione materiae, que debido a exigencias políticas requiere de una reforma inminente; resultaría absurdo no

25 El párrafo tercero del artículo 75 de la Constitución excluye la aplicación de esta variante procedimental para legislar determinados ámbitos materiales. "Quedan exceptuadas de lo dispuesto en el apartado anterior la reforma constitucional, las cuestiones internacionales, las leyes orgánicas y de bases y los Presupuestos Generales del Estado». 
hacer uso de un expediente técnico como la declaración de urgencia para agilizar la legislación en respuesta a la demanda generada. Nadie parece poner en duda que la aplicación genérica del procedimiento de urgencia confiere a las Asambleas mayor funcionalidad en el ejercicio de sus competencias.

Desde una perspectiva más general, encontramos otras razones que abogan por esta postura. Debemos tener en cuenta que de los tres procedimientos legislativos especiales por razón temporal, tan sólo el de competencia legislativa plena en Comisión tiene excluida su aplicación a determinadas materias tasadas constitucionalmente (art. 75.3 CE). Por otra parte, el régimen jurídico de la tramitación de lectura única, pese a no prever límites materiales explícitos, parece apuntar a supuestos de hecho lo suficientemente consensuados como para justificar la supresión de la fase de examen en Comisión ${ }^{26}$. En consecuencia, teniendo en cuenta estos datos, el mecanismo de urgencia quedaría como la única técnica libre de condicionantes materiales, capaz de permitir una aceleración procedimental ante circunstancias políticas apremiantes. El único reparo que podría plantearse a esta opción es el derivado del abuso de este tipo de técnicas procedimentales, en la medida en que no podemos olvidar que una aceleración excesiva de la tramitación siempre va acompañada de menor tiempo de discusión de los textos, y por tanto, de menores posibilidades para que los parlamentarios, especialmente la oposición, puedan participar en los mismos. Sin embargo, haber incorporado este tipo de restricciones materiales a la tramitación de urgencia hubiera supuesto convertir el proceso de adopción de decisiones legislativas en un sistema aún más rígido, al privar al Parlamento de un instrumento que le permite reaccionar de forma ágil a las demandas legislativas sobrevenidas.

\subsection{Ausencia de limites temporales}

La práctica parlamentaria se ha encargado de poner de manifiesto otra de las controvertidas cuestiones que plantea la tramitación del procedimiento de urgencia, cual es la relativa a la existencia o no de límites temporales, o expresado en otros términos, si la declaración de la urgencia, como requisito necesario para la activación de esta especialidad, debe tener lugar necesariamente con carácter previo al inicio de la tramitación en el Congreso de los Diputados o si también puede acontecer en otro momento procesal posterior de forma sobrevenida.

${ }^{26}$ Este es el sentido del artículo 150.1 del Reglamento del Congreso al disponer que se acordará este procedimiento «cuando la naturaleza del proyecto o proposición de ley tomada en consideración lo aconsejen o su simplicidad de formulación lo permita...». 
La cuestión a la que estamos aludiendo llegó hasta el Tribunal Constitucional en uno de los escasos conflictos de atribuciones entre órganos constitucionales que ha tenido que resolver dicha institución; conflicto, promovido por el Gobierno contra el Senado en relación con el Acuerdo de la Mesa de dicha Cámara por la que se inadmitió a trámite la declaración de urgencia del Gobierno relativa a la tramitación del proyecto de Ley Orgánica sobre regulación de la interrupción voluntaria del embarazo, por vulnerar los artículos 90.3 CE y 133.1 del Reglamento del Senado. En esta ocasión y ante la negativa del órgano rector del Senado a dar curso a la activación y tramitación del proyecto declarado urgente por el Gobierno, éste requirió la revocación del Acuerdo de la Mesa por entender que la Cámara Alta era incompetente a tal efecto; requerimiento, que fue rechazado por ésta al considerar que la facultad reconocida al Gobierno por el artículo 90.3 CE debía producirse «con anterioridad al inicio de dicha tramitación de los proyectos de ley en el Congreso de los Diputados» y, por tanto, ratificó la decisión parlamentaria impugnada. Ante esta situación el Gobierno decidió promover conflicto constitucional de atribuciones contra el Acuerdo de la Mesa del Senado por entender que se invadían las facultades que le concede el artículo $90.3 \mathrm{CE}$ para declarar urgente un proyecto de ley de forma originaria o sobrevenida.

Hechas estas consideraciones, el asunto fue resuelto en la STC 234/2000 ${ }^{27}$ a través de la cual el Tribunal Constitucional resolvió las discrepancias planteadas entre el Gobierno y el Senado en torno a la interpretación del artículo 90.3 CE, concretamente, sobre la existencia o no de límites temporales al ejercicio de la facultad de declarar la urgencia de los proyectos de ley que la Constitución reconoce al Gobierno. Frente a la argumentación de la representación del Senado a favor de la existencia de dichas restricciones temporales, el Tribunal se manifiesta en contra de esta tesis sosteniendo, por el contrario, la ausencia de límites de esta naturaleza. «Del propio tenor del art. 90.3, pues, no resulta el límite temporal que se aduce a la facultad del Gobierno de declarar la urgencia de los proyectos de ley con los efectos que a tal declaración se anudan en el precepto constitucional» (STC 234/2000, FJ 11). Según se expresa en la resolución tal limitación temporal «no resulta tampoco de un examen teleológico o finalista del mecanismo puesto a disposición, en este caso, del Gobierno para abreviar el tiempo normal de tramitación en el Senado de los proyectos de

27 Sobre esta sentencia puede verse el trabajo de TORRES MURO, I., «¿Subordinando al Senado? La declaración gubernamental de urgencia, ex art. 90.3 CE, ante el Tribunal Constitucional (STC 234/2000)", Repertorio Aranzadi del Tribunal Constitucional, 2000, n. ${ }^{\circ} 3$, pp. 1883 1903. 
ley al objeto de agilizar su tramitación parlamentaria y de este modo obtener, en un plazo más reducido al establecido con carácter general, aquellas medidas legislativas que propone a las Cámaras. En la urgencia, pues, que el Gobierno atribuye a un determinado Proyecto de ley estriba la razón y el fundamento último de la facultad que al Gobierno confiere el art. 90.3 CE, siendo claro, como reconoce la representación del Senado, que dicha urgencia puede ser percibida por el Gobierno tanto en el momento de depositar el proyecto de ley en el Congreso de los Diputados como en un momento posterior, iniciada ya la tramitación parlamentaria del mismo, como consecuencia de cambios de circunstancias» (FJ 11\%).

Por tanto, el Tribunal concluye, acertadamente a nuestro juicio, descartando la existencia de justificación alguna de la que pueda deducirse un límite temporal, por lo que termina admitiendo tanto la aplicación originaria (al inicio de la tramitación), como la activación sobrevenida del procedimiento de urgencia (una vez iniciada aquélla).

\subsection{Simultaneidad con otros procedimientos legislativos}

La posibilidad de aplicar simultánea o transversalmente ${ }^{28}$ el procedimiento de urgencia con otras variantes ha suscitado la cuestión de si esta modalidad de tramitación urgente puede combinarse también con otras especialidades procedimentales, incluidas las que derivan la peculiaridad por razón del tiempo de tramitación.

Ya señalamos anteriormente que la simultaneidad de la urgencia con los procedimientos especiales por razón material no suscita problema alguno, habida cuenta de la ausencia de límites materiales a su aplicación. Sin embargo, la compatibilidad con las especialidades derivadas del elemento temporal genera algunas dudas. Para abordar esta cuestión debemos traer a colación el debate acerca de la tipificación de la urgencia como procedimiento legislativo autónomo, especial, o como mera norma de funcionamiento de la Cámara. Por tanto, para profundizar en esta problemática debemos tener en cuenta esta discusión sobre la naturaleza procedimental de la urgencia que divide a la doctrina entre quienes consideran que se trata de un procedimiento autónomo y

${ }^{28}$ Entre los términos utilizados por la doctrina para referirse a esta posibilidad de combinación de varios procedimientos legislativos, P.García-Escudero emplea la expresión «aplicación transversal». Consúltese GARCía-EsCudero MÁrQueZ, Piedad, El procedimiento legislativo ordinario en las Cortes Generales, op. cit., p. 110. 
quienes estiman que se trata de una mera norma de funcionamiento. Recordemos que para los partidarios de esta última postura doctrinal, la regulación del Reglamento del Congreso posibilita la aplicación de la declaración de urgencia junto al procedimiento de comisión con competencia legislativa ple$\mathrm{na}^{29}$.

La práctica parlamentaria nos ofrece múltiples muestras del uso coetáneo de los procedimientos de urgencia y delegación de competencia legislativa en Comisión por parte de las Cámaras, e incluso de aquél junto al método de lectura única. Esta simultaneidad resulta más acuciante en el Congreso de los Diputados donde el Reglamento, como hemos señalado, regula la urgencia como mera norma de funcionamiento interno ubicándola fuera del Título sobre el procedimiento legislativo. Por otra parte, esta opción se ha visto avalada por la Jurisprudencia Constitucional contenida en la STC 234/2000. Precisamente esta interpretación constitucional del artículo $90.3 \mathrm{CE}$ como regla de funcionamiento constituye una de las razones esgrimidas para compatibilizar estas dos modalidades procedimentales. En nuestra opinión se trata de una postura que conlleva ciertos riesgos inherentes a una excesiva aceleración de la tramitación parlamentaria, como por ejemplo la merma de algunos de los principios parlamentarios clásicos o la limitación de los derechos de las minorías que verían recortadas sus posibilidades reales de actuación en el procedimiento legislativo. En consecuencia, y para evitar estos riesgos, insistimos en que la urgencia debería regularse como procedimiento autónomo no compatible con otras modalidades de su misma especie, evitando la duplicidad de aplicación de varios procedimientos especiales caracterizados por la agilización procedimental.

No puede olvidarse que la previsión normativa de instrumentos de aceleración de la tramitación parlamentaria no garantiza por sí sola el objetivo de aprobar leyes de un modo más ágil, ya que ello dependerá de otros factores como la actitud de los Grupos parlamentarios y, sobre todo, de la ausencia de un uso obstruccionista de los mismos. Es indudable, que la voluntad de los órganos parlamentarios que intervienen en el ejercicio de la función legislativa influye en el resultado final de los procedimientos.

${ }^{29}$ Así lo admite Villacorta Mancebo, op. cit., p. 447. En el mismo sentido se pronuncia también BASTERRA MONTSERRAT, quien considera que en el caso del Senado la ausencia de regulación por el Reglamento de la Cámara, la Mesa podría decretar la urgencia cuando se produce la delegación legislativa a las Comisiones «basándose en lo dispuesto en el art.133.2 del Reglamento del Senado», op. cit., p. 94. 


\subsection{El procedimiento del articulo 136 del Reglamento del Senado}

Por último, queremos hacer una breve referencia a otra especialidad procedimental recogida en el artículo 136 del Reglamento del Senado y que se presenta como variante específica dentro del procedimiento de urgencia. Se trata de otro supuesto excepcional en el que la tramitación del procedimiento en el Senado queda reducida a un mes, convirtiéndose en una modalidad alternativa a la de los veinte días, que puede ser adoptada por la Mesa de la Cámara, a propuesta de la Junta de Portavoces, sólo en el caso de que «...no resulte aplicable lo dispuesto en el artículo 133...", esto es, únicamente si la declaración de urgencia es acordada por la Mesa del Senado, único supuesto en que puede optar por uno u otro ${ }^{30}$. Debe tenerse en cuenta que en esta modalidad los plazos no son naturales, como sucede en el procedimiento de urgencia, sino hábiles, lo cual alarga más la tramitación parlamentaria en el Senado. Esta variante procedimental ha recibido por parte de la doctrina diferentes denominaciones, como procedimiento acelerado ${ }^{31}$ o procedimiento de semiurgencia ${ }^{32}$, si bien utilizaremos la expresión "procedimiento de un mes»; nomenclatura, utilizada por las Memorias de Legislatura del Senado. En definitiva, se trata de una vía intermedia entre el procedimiento ordinario de elaboración de leyes y el procedimiento de urgencia.

De la práctica legislativa de la Cámara Alta se constata que se trata de una modalidad procedimental poco utilizada; desde la entrada en vigor del Reglamento del Senado de 1982 ha sido aplicada tan sólo en veintiséis ocasiones (veinticinco proyectos y una proposición de ley) a contar desde la III Legislatura (1986-1989) ${ }^{33}$. Con la única excepción de las dos primeras veces en que se empleó esta vía (en la II Legislatura) y la tramitación de la proposición de Ley de Solidaridad con las víctimas del terrorismo (durante la VI Legislatura), se verifica que, desde la IV Legislatura, los restantes proyectos de ley tramitados conforme al procedimiento de un mes corresponden a las Leyes de Presupuestos Generales del Estado y a las leyes de medidas fiscales, administrativas y de orden social, co-

30 Consúltese García MartíneZ, op. cit., p. 302.

31 Véase Esteban Alonso, Jorge de, y González-Trevijano, Pedro, Curso de Derecho Constitucional español, III, Madrid, Servicio de Publicaciones de la Facultad de Derecho UCM, 1994; Álvarez Conde, Curso de Derecho Constitucional, II, Madrid, Tecnos, 2005.

32 García-Escudero MÁrQuez, Piedad, «El procedimiento legislativo en las Cortes Generales: regulación, fases y tipos», Teoría y Realidad Constitucional, n. ${ }^{\circ}$ 16, 2005, p. 238.

33 Estos datos pueden consultarse en las Memorias correspondientes a la I, II, III, IV, V, VI y VII Legislaturas del Senado. 
nocidas popularmente como Leyes de acompañamiento ${ }^{34}$, que con anterioridad eran aprobadas por el procedimiento de urgencia ${ }^{35}$.

\section{EL PROCEDIMIENTO DE URGENCIA EN LOS PARLAMENTOS AUTONÓMICOS}

El Legislador autonómico ha optado por incorporar este procedimiento en los Reglamentos de las Asambleas legislativas autonómicas ${ }^{36}$. Aunque no vamos a analizar pormenorizadamente la normativa de estos Reglamentos, sí que quisiéramos realizar un breve comentario sobre algunas curiosidades de esta regulación. La rúbrica y sistemática que han utilizado para referirse a esta modalidad varía de unos casos a otros.

Todos los Reglamentos parlamentarios de ámbito autonómico regulan la urgencia junto a las disposiciones normativas relativas al funcionamiento interno de las Asambleas, con la única excepción del Parlamento vasco. De entre ellos, los Reglamentos de la Asamblea de Madrid y del Parlamento de Navarra disci-

34 Sobre la problemática que estas leyes suscitaron en nuestra doctrina nos remitimos a CAZORLA PRIETO, Luís María, Las llamadas leyes de acompañamiento presupuestario, Madrid, Instituto de Estudios Fiscales-Marcial Pons, 1998. Puede consultarse una breve exposición de esta categoría legislativa en GARCÍA DE ENTERRIA, Eduardo, Justicia y seguridad jurídica en un mundo de leyes desbocadas, Madrid, Cuadernos Civitas, 1999, pp. 77-89.

35 Efectivamente, las Leyes de Presupuestos Generales del Estado para 1979, 1980, 1981, 1982, 1983, 1984, 1985, 1986, 1987, 1988 y 1989 fueron tramitadas y aprobadas en el Senado siguiendo el procedimiento de urgencia, simultáneamente al procedimiento presupuestario.

36 Véase Reglamento del Parlamento de Andalucía de 26 de abril de 1995 (arts. 98 y 99); el de las Cortes de Aragón de 26 de junio de 1997 (art. 107); el de la Junta General de Asturias de 18 de junio de 1997 (arts. 122 y 123); el del Parlamento de las Islas Baleares de 6 de junio de 1986, reformado por última vez el 20 de marzo de 1991 (arts. 95 y 96); el del Parlamento de Canarias de 28 y 29 de marzo de 1995, reformado el 26 de mayo de 2003 (arts. 102 y 103); el de la Asamblea Regional de Cantabria de 16 de mayo de 1984, reformado por última vez el 17 de septiembre de 2001 (arts. 89 y 90); el de las Cortes de Castilla-La Mancha de 16 de octubre de 1997, reformado el 10 de octubre de 2002 (arts. 122); el de las Cortes de Castilla-León de 11 de mayo de 2005 (arts. 97 y 98) el del Parlamento de Cataluña de 22 de diciembre de 2005 (art. 96); el de la Asamblea de Extremadura de 14 de septiembre de1993, reformado por última vez el 11 de septiembre de 2003 (art. 97 y 98); el del Parlamento de Galicia de 1 de septiembre de 1983, reformado el 4 de enero de 1995 (arts. 98 y 99); el de la Asamblea de Madrid de 30 de enero de 1997 (arts. 132); el de la Asamblea de Murcia de 14 de abril de 1988, reformado el 13 de junio de 2002 (art. 113); el del Parlamento de Navarra de 2 de febrero de 1995, reformado el 21 de junio de 2005 (arts. 108 y 109 ); el del Parlamento Vasco de 11 de febrero de 1983 (arts. 121 y 122); el de la Diputación General de la Rioja de 18 de abril de 2001 (art. 79) y el de las Cortes Valencianas de 30 de junio de 1994 (arts. 88 y 89). 
plinan la urgencia como "procedimiento» y no como "declaración», mientras que los restantes optan por la forma de la «declaración de urgencia». Sin embargo, de esta distinción formal no cabe extraer consecuencias relevantes para la naturaleza de esta modalidad de tramitación, en la medida en que todos ellos, independientemente de la forma concreta (declaración o procedimiento), incorporan estas normas entre las disposiciones generales de funcionamiento de las Cámaras, de donde se desprende que la urgencia se articula como mera regla parlamentaria de aplicación genérica a cualquier asunto y procedimiento, independientemente de su naturaleza; o expresado en otros términos, su aplicación no se limitaría exclusivamente al ámbito del iter legis, sino que abarcaría cualquier modalidad de procedimiento parlamentario.

Por tanto, el único Reglamento parlamentario que concede una forma diferente a la urgencia es el del Parlamento Vasco, cuyas previsiones incluyen esta variante en su Título VI, dedicado al Procedimiento Legislativo, por lo que circunscribe esta especialidad procedimental a la actividad legislativa, descartando su aplicación a las restantes actividades de la Cámara. Con ello, el Reglamento vasco ha optado explícitamente por otorgar a la urgencia un tratamiento jurídico de auténtico procedimiento de naturaleza legislativa, e independiente del ordinario, como se deriva de su regulación en un capítulo (III) separado del referente al procedimiento legislativo común (I) y de las especialidades del procedimiento legislativo (II). En nuestra modesta opinión, esta opción minoritaria parece más respetuosa con la naturaleza de la urgencia como procedimiento alternativo al común.

Por último, quisiéramos llamar la atención sobre el Reglamento de la Asamblea de Murcia por su curioso e innovador tratamiento jurídico y sistemática, no sólo de la urgencia, sino de las restantes especialidades procedimentales legislativas por razón temporal. El Capítulo IX del mismo (De la declaración de urgencia) ${ }^{37}$ ofrece la posibilidad de tramitar los asuntos parlamentarios conforme

37 Artículo 113:

1. Al decidir los aspectos concretos de la tramitación que deba darse a un asunto, el Consejo de Gobierno, la Mesa de la Asamblea y un Grupo Parlamentario de los constituidos al inicio de la legislatura, y en relación con un asunto que se tramite a instancias de éste, podrán sugerir, o la Junta de Portavoces directamente acordar, que dicha tramitación se realice por el procedimiento de urgencia. A tal efecto podrá optarse por alguno de los sistemas siguientes:

a) Declaración de carácter prioritario sobre cualquier otro asunto que no tenga atribuida dicha cualidad.

b) Reducción de plazos hasta un máximo de la mitad del término establecido.

c) Debate a término fijo, de tal modo que, transcurrido el tiempo señalado de antemano, se pase a efectuar las votaciones que queden pendientes. 
al procedimiento de urgencia, ofreciendo una pluralidad de variantes para elegir: a) tramitación preferente, b) reducción de los plazos ordinarios a la mitad, c) debate con tiempos tasados (se asimila a la técnica de la guillotina), y d) lectura única ante el Pleno. La normativa atribuye la capacidad de activar cualquiera de estas modalidades a la Junta de Portavoces, de oficio o a instancia del Consejo de Gobierno, la Mesa de la Asamblea o un Grupo Parlamentario de los constituidos al inicio de la legislatura (art. 113.1). Además, se habilita la posibilidad de aplicar simultáneamente dos o más de las técnicas incluidas en este precepto, si ello es compatible; decisión que también deberá acordar la Junta de Portavoces.

En definitiva, se constata como la mayoría de los Reglamentos parlamentarios autonómicos han optado por la fórmula sistemática empleada por el Reglamento del Congreso de los Diputados: «De la declaración de urgencia». Éste es el caso de los Reglamentos de las Asambleas de las siguientes Comunidades Autónomas: Andalucía, Aragón, Asturias, Islas Baleares, Canarias, Cantabria, Castilla-La Mancha, Castilla-León, Cataluña, Extremadura, Galicia y Valencia. En otros Reglamentos se hace referencia de forma expresa al «procedimiento de urgencia", como ocurre en el caso de las Comunidades de Madrid, Navarra, País Vasco y en el anterior Reglamento de La Rioja.

En cuanto a las especialidades que se aplican en esta tramitación parlamentaria, en todos los casos consiste en la misma limitación de plazos que se sigue en los Reglamentos del Congreso de los Diputados y del Senado, es decir, en la reducción a la mitad de los plazos ordinarios previstos para el procedimiento base. Respecto a los sujetos legitimados para activar la declaración o procedimiento de urgencia, en términos generales los Reglamentos de las Asambleas autonómicas optan por una regulación bastante próxima a las normas referentes a las Cámaras nacionales. Por lo que se refiere a la legitimidad para acordar esta modalidad de tramitación, todos los Reglamentos atribuyen unánimemente dicha facultad a la Mesa de la Asamblea, que actuará únicamente a solicitud del Gobierno autonómico, los Grupos parlamentarios (exigiéndose un número que varía entre uno y tres) y un número mínimo de parlamentarios (una quinta parte o una décima parte, dependiendo de los casos). De entre estos Reglamentos, destaca el de las Cortes de Castilla y León que adjudica la adopción de la urgencia a la Mesa con la intervención previa de otro órgano parlamentario, al exigir "previo acuerdo de

d) Lectura única directamente en el Pleno, sujeta a un solo debate de totalidad sin discusión de enmiendas y concluida con una sola votación sobre el proyecto o documento considerado en su conjunto.

2. Cuando dos o más medidas de las contempladas en el apartado anterior sean compatibles, la Junta de Portavoces podrá acordarlas con carácter complementario, siempre que la urgencia del tema o proyecto lo requiera. 
la Junta de Portavoces» (art. 97.1). En este supuesto, entendemos que lo que es preceptivo es la intervención de dicho órgano pero ello no implica que el acuerdo que emita tenga que ser favorable a la declaración de la urgencia; nada de eso parece deducirse del precepto señalado. Por último, debemos destacar de nuevo el Reglamento de la Asamblea de Murcia, cuya normativa sobre este extremo se aparta radicalmente de esta homogeneidad. En efecto, en este supuesto no será el órgano rector de la Asamblea, sino la Junta de Portavoces la instancia encargada de adoptar la tramitación de urgencia; eventualidad que podrá llevarse a cabo no sólo a petición de los órganos señalados (Consejo de Gobierno, Mesa de la Asamblea y un Grupo Parlamentario de los constituidos al inicio de la legislatura), sino también de oficio, posibilidad no reconocida al órgano correspondiente por el resto de Reglamentos de Parlamentos autonómicos.

\section{CONSIDERACIONES FINALES}

En las páginas que preceden se ha analizado el significado de la «declaración de urgencia» en el procedimiento legislativo como técnica de agilización procedimental. Asimismo se ha procedido a examinar el régimen jurídico de este procedimiento legislativo especial previsto en nuestro derecho positivo. Tras este estudio, se hace preciso destacar algunos aspectos que han llamado nuestra atención.

En términos generales, el juicio que nos merece la existencia de este mecanismo, como técnica de agilización procedimental es positivo, si bien todo depende una vez más del uso que se realice del mismo. A nuestro modo de ver, la normativa del Reglamento del Congreso de los Diputados debería modificarse con el objeto de regular este procedimiento dentro del capítulo dedicado a las especialidades del procedimiento legislativo, como hace el Reglamento de la Cámara Alta; con esta nueva sistemática se evitarían las dudas doctrinales surgidas acerca de la naturaleza de esta técnica, descartando su consideración como mera norma de funcionamiento.

Del análisis realizado se colige que esta técnica se ha convertido en un cauce alternativo al iter legis ordinario cuando las circunstancias políticas o sociales requieren de una rápida intervención legislativa por parte del Parlamento; celeridad, que no deriva exclusivamente de la acumulación habitual de tramitaciones legislativas en las Cámaras, sino también de otro tipo de circunstancias, como el propósito de evitar la caducidad de las iniciativas legislativas en curso en el supuesto de disolución de las Cámaras. Desde esta perspectiva, podemos confirmar que nuestro ordenamiento jurídico cuenta con instrumentos jurídicos suficientes para permitir una actuación urgente del Legislador. Las normas parlamen- 
tarias dotan a las Cámaras de procedimientos idóneos, entre los que se encuentra el de urgencia, para hacer frente a las circunstancias políticas más diversas y a la sobrecarga legislativa. Sin embargo, la aplicación de este cauce particularizado no está exenta de dificultades, fundamentalmente las que se derivan para las minorías parlamentarias, como hemos señalado en diversas ocasiones. En este sentido, hemos tratado de poner de relieve como el problema reside en el uso del procedimiento, lo que nos lleva a recordar de nuevo que su aplicación deberá realizarse con cautela y de forma excepcional. La utilización de la urgencia en el iter legis debe efectuarse siempre dentro del marco que delimitamos al principio de este trabajo, es decir, respetando los principios que rigen, no sólo el modo de creación de las leyes, sino cualquier procedimiento parlamentario. Por ello, queremos terminar este apartado, haciendo un alegato a la prudencia con la que debe emplearse esta técnica procedimental puesta a disposición del Gobierno y la mayoría parlamentaria que lo apoya, de tal modo que se logre un uso racional de la misma que permita un equilibrio entre dos extremos: el bloqueo de la función de indirizzo politico del Gobierno y la vulneración de los derechos de la minoría a participar en los procedimientos parlamentarios. Ciertamente, la aplicación de mecanismos como el procedimiento de urgencia vendrá a su vez condicionada por diversas variables tales como la naturaleza del texto en tramitación, la composición de las Cámaras o la finalidad perseguida por los impulsores del procedimiento.

Asimismo la praxis parlamentaria pone de manifiesto que se trata de un procedimiento utilizado principalmente en el Senado, y con menor frecuencia en el Congreso de los Diputados. Las razones que explican este dato no derivan únicamente del escaso margen temporal con que cuenta la Cámara Alta para el examen, discusión y aprobación de las leyes, sino también de la regla prevista por el artículo 133.1 RS que impone su activación cuando los proyectos hayan sido declarados urgentes por el Congreso de los Diputados; es decir, en nuestro derecho parlamentario vigente el número de iniciativas legislativas tramitadas conforme a esta modalidad en la Segunda Cámara siempre será superior a las que han seguido la misma técnica procedimental en el Congreso porque la norma reglamentaria señalada dispone la automaticidad y obligación de su aplicación, cuando previamente ha sido declarada la urgencia en la Cámara baja, dando lugar a un supuesto de vinculación procedimental entre ambas ramas del Parlamento. Por otra parte, los datos estadísticos sobre las iniciativas tramitadas conforme a esta modalidad confirman que se trata del procedimiento legislativo especial por razón temporal más empleado en la Cámara Alta; ello resulta fácilmente comprensible a la luz de los rigurosos y estrictos plazos impuestos por la Constitución para la tramitación legislativa en esta Cámara. 


\title{
Title
}

The urgency in the iter legis: a Government's technique to speed the legislative procedure

\section{Resumen}

El procedimiento de urgencia es uno de los diferentes procedimientos legislativos especiales existentes en nuestro ordenamiento. Constituye una técnica de agilización del iter legis que el Parlamento puede utilizar cuando las circunstancias políticas exigen una respuesta legislativa urgente. Su especialidad consiste en que los plazos ordinarios para la aprobación de la ley son reducidos a la mitad en el Congreso y a veinte días naturales en el Senado. De este modo se produce un acortamiento de la tramitación y un ahorro de trámites parlamentarios.

El presente trabajo tiene por objeto el análisis del régimen jurídico del procedimiento legislativo especial de urgencia en Derecho parlamentario español. Asimismo se estudia el papel del Gobierno en esta técnica legislativa, ya que se trata de uno de los sujetos que pueden pedir la aplicación de este procedimiento a través de la declaración de urgencia.

\begin{abstract}
The urgency methode is one of the several special legislative procedures in the Spanish legal system. It constitutes a technique to speed up the iter legis that the Parliament could use it in political circumstances that demands an urgent legislative solution. Its main speciality involves in that all parliamentary terms to pass the bill are reduced to half in Congress and to twenty days in Senate. And, in that order, it saves time and produces a reduction of the legislative procedure.

This paper examines the urgency special legislative procedure in the Spanish Parliamentary law. We will analyse the Government's roll in this legislative technique, because it can be used if the Government declares the urgency of the bill.
\end{abstract}

\section{Palabrtas clave}

Parlamento, legislación, procedimiento legislativo, declaración de urgencia

\section{Key words}

Parliament, Legislation, Legislative procedure, Urgency declaration 